Abstract 641 Table 4 Risk factors associated with stroke events (Multivariate analysis)

\begin{tabular}{|c|c|c|c|c|c|c|c|c|}
\hline Risk Factor & coef & explcoeff) & se(coef) & $\begin{array}{l}\text { coeflower } \\
95 \%\end{array}$ & $\begin{array}{l}\text { coef upper } \\
95 \%\end{array}$ & $\begin{array}{l}\text { exp(coef) } \\
\text { lower } 95 \%\end{array}$ & $\begin{array}{l}\text { expp(coeff) } \\
\text { upper 95\% }\end{array}$ & Pvalue \\
\hline Lung cancer & 0.19 & 1.22 & 0.15 & -0.10 & 0.50 & 0.89 & 1.65 & 0.19 \\
\hline $\begin{array}{c}\text { Head and neck } \\
\text { squamous cell cancer }\end{array}$ & -1.16 & 0.31 & 0.51 & -2.17 & -0.14 & 0.11 & 0.86 & 0.02 \\
\hline Malignant melanoma & 0.44 & 1.56 & 0.16 & 0.12 & 0.76 & 1.13 & 2.15 & 0.00 \\
\hline Monotherapy : PD-1 & -0.28 & 0.74 & 0.15 & -0.59 & 0.01 & 0.55 & 1.01 & 0.06 \\
\hline Monotherapy : CTLA-4 & 0.25 & 1.28 & 0.16 & -0.06 & 0.57 & 0.93 & 1.77 & 0.12 \\
\hline \begin{tabular}{|l|} 
Chronic Obstructive \\
Pulmonary Disease \\
\end{tabular} & -0.01 & 0.98 & 0.11 & -0.23 & 0.20 & 0.79 & 1.22 & 0.89 \\
\hline Peptic Ulcer Disease & -0.85 & 0.42 & 0.41 & -1.66 & -0.04 & 0.19 & 0.95 & 0.03 \\
\hline
\end{tabular}

Conclusions To the best of our knowledge, this is the largest and comprehensive real-world longitudinal study for stroke events in advanced cancer patients treated with ICI. Cumulative incidence of stroke was significantly higher in patients on anti-CTLA-4 monotherapy and anti-CTLA-4 plus anti-PD-1 combination therapy in comparison to anti-PD-1/PD-L1 monotherapy. Malignant melanoma and anti CTLA-4 therapy were independent risk factors for stroke.

Acknowledgements This work was funded by pilot award in Big Data/Cancer Informatics to Prantesh Jain, MD from University Hospitals Research \& Education Institute

Ethics Approval The IBM MarketScan national database contains de-identified linked inpatient, outpatient, and pharmacy claims data. University Hospitals' Institutional Review Board determined this study to be exempt from review and requirement of an informed consent.

http://dx.doi.org/10.1136/jitc-2020-SITC2020.0641

\section{RETROSPECTIVE REVIEW OF PULMONARY PATHOLOGY ASSOCIATED WITH CHIMERIC ANTIGEN RECEPTOR T CELL THERAPY}

${ }^{1}$ Jing Du*, ${ }^{2}$ David Woolston, ${ }^{3}$ Kimberly Costas, ${ }^{2}$ Alexandre Hirayama, ${ }^{2}$ Cameron Turtle, ${ }^{2}$ Cecilia Yeung. 'University of Washington, Seattle, WA, USA; ${ }^{2}$ Fred Hutchinson Cancer Research Center, Seattle, WA, USA; ${ }^{3}$ Providence Medical Group, Everett, WA, USA

Background Chimeric antigen receptor (CAR) T-cell therapy is an immunotherapy which uses genetically modified $T$ cells engineered to express CARs to recognize and kill cells that harbor specific antigens. CAR T-cell products designed to target the tumor specific antigens have been used for the treatment of relapse and/or refractory of acute lymphoblastic leukemia, non-Hodgkin lymphomas, myeloma, and solid tumor in clinical trials at our institution. Several side effects have been reported including increased risk of infection.

Methods Retrospective review of morphologic, microbiologic and flow cytometric evaluations done on bronchioalveolar lavages (BAL), pleural effusions, and tissue biopsy specimens from post CAR T-cell adult patients with respiratory complications at our institution from March 2013 to January 2020.

Results Thirteen cases with BAL, 8 cases with biopsy (including lymph node and lung tissue) and 5 cases with pleural effusion are reviewed. All infectious diseases were detected on BAL specimens; while primary disease involvements were mainly seen on biopsy and pleural effusion specimens (figure 1). Interestingly, we found a case of a patient with refractory diffuse large B cell lymphoma that had developed mediastinal lymphadenopathy 9 months after CD19 CAR T-cell infusion (defined composition CD4 and CD8 CAR T-cells). Subsequent biopsies showed granulomatous inflammation with minimal
Respiratory complicatons in different types of specimens

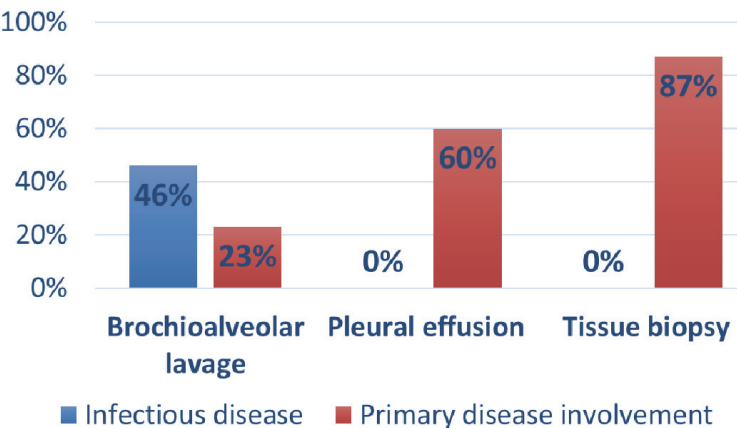

Abstract 642 Figure 1 Infectious complications were only observed in BAL specimens, while primary disease involvement post-CAR-T cell therapy was mostly observed in pleural effusions and tissue biopsies

evidence of necrosis (figure 2). Special stains with AFB, Gram, Warthin Starry, and Wright Giemsa showed no evidence of infectious organisms. Special stains were negative for acid fast, fungal, bacterial, or spirochetal organisms. Polymerase chain reaction for Mycobacterium tuberculosis complex DNA by hsp65 amplified probe, and nontuberculous mycobacteria (including Mycobacterium avium complex) by $16 \mathrm{~s}$ rDNA, hsp65, and rpoB pruner sets were both negative. No abnormal $\mathrm{B}$ or $\mathrm{T}$ cell population was found by concurrent flow cytometry; however, CAR T-cells were detected at low levels.

Conclusions Granulomatous inflammation is a chronic, histiocytic response to various chemical mediators of cell injury caused by broad etiologies. $\delta \gamma \mathrm{T}$ cells and $\mathrm{T}$ helper cells play roles on recruiting circulating monocytes and maturating of macrophages and ultimately the formation of granulomas. In our case, the patient has no documented autoimmune disease. Extensive infectious disease work-ups failed to identified infectious etiology. The presence of CAR T-cells in mediastinal lymph node 9 months after infusion is not unexpected given CAR T-cells can be detected in the blood for years in some patients. The granulomatous inflammation can be part of exaggerated tissue repair process after lymphoma cells killed by CAR T-cells. However, it may complicate or even mislead

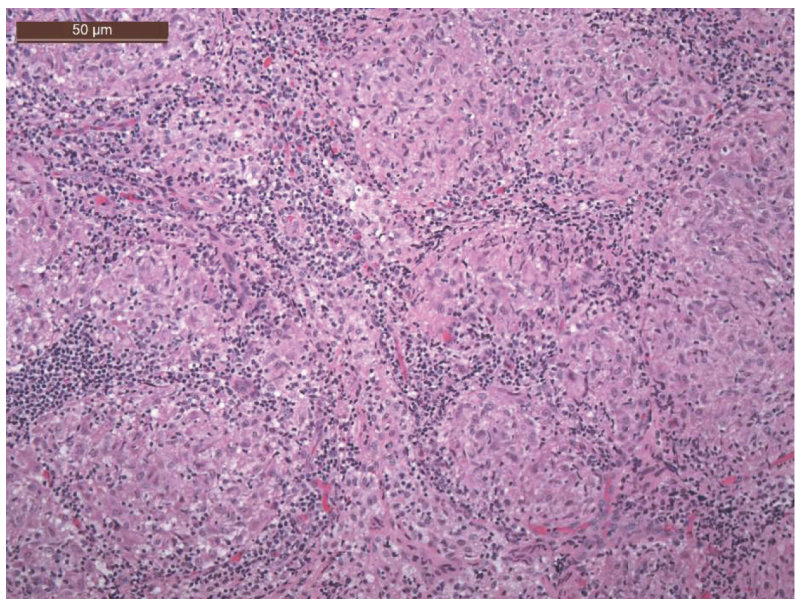

Abstract 642 Figure 2 Hematoxylin and eosin stain of a lymph node biopsy from 329 days post-CAR-T cell infusion (10x magnification) demonstrating extensive noncaseating granulomatous inflammation 
assessment of therapeutic effect on post-CAR T-cell cases. The finding of enlarged lymph nodes by imaging study certainly raises concern of disease persistent or relapse.

Ethics Approval The study was approved by Fred Hutchinson Cancer Research Center's Ethics Board, approval numbers 1837, 9364

Consent Written informed consent was obtained from the patient for publication of this abstract and any accompanying images. A copy of the written consent is available for review by the Editor of the this journal.

http://dx.doi.org/10.1136/jitc-2020-SITC2020.0642

\section{AUTOPSY REVIEW OF CHIMERIC-ANTIGEN RECEPTOR T CELL THERAPY: A SINGLE INSTITUTION EXPERIENCE}

${ }^{1}$ KiBeom Kwon, ${ }^{2}$ David Woolston, ${ }^{2}$ Alexandre Hirayama, ${ }^{2}$ Damian Green, ${ }^{2}$ David Maloney, ${ }^{2}$ Cameron Turtle, ${ }^{2}$ Cecilia Yeung*. 'Seattle Cancer Care Alliance, Seattle, WA, USA; ${ }^{2}$ Fred Hutchinson Cancer Research Center, Seattle, WA, USA

Background Our institution has treated over 300 patients with chimeric antigen receptor (CAR) T-cell immunotherapy (CAR T-cell therapy) since 2013. Phase I and II trials were primarily based on heavily treated patients with B cell acute lymphoblastic leukemia (B-ALL), aggressive diffuse large B cell lymphoma (DLBCL), and multiple myeloma (MM) who had failed multiple lines of prior chemotherapy and/or hematopoietic stem cell transplantation (HSCT). In these relapsed and/or refractory patients, CAR-T therapy resulted in complete remission in $93 \%$ of B-ALL, $60 \%$ of DLBCL, and $\sim 80 \%$ of MM. Our Pathology Group at Fred Hutch have reviewed and diagnosed various patients with interesting relapse or complications as a result of CAR T-cell therapy. Here we present a retrospective review of autopsies from CAR T-cell therapy.

Methods A search for all autopsies conducted on patients from Seattle Cancer Care Alliance/University of Washington Medical Center was performed using the keywords 'CAR T' and 'Chimeric-antigen'. Our inclusion criteria were patients treated with CAR T-cell therapy. Pathology and clinical records were reviewed for cause of death, disease and treatment

Abstract 643 Table 1 Patient characteristics: age, sex, original diagnosis, CAR target, cause of death, and days post-CAR T-cell infusion at time of death

\begin{tabular}{|c|c|c|c|c|c|c|}
\hline 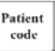 & $\begin{array}{r}\text { Age at } \\
\text { death }\end{array}$ & Gender & $\begin{array}{c}\text { Original } \\
\text { diagnesis }\end{array}$ & CAR target & $\begin{array}{c}\text { Days post- } \\
\text { CAR infusion } \\
\text { upon death }\end{array}$ & Cause of Death \\
\hline 1 & 65 & м & DLBCL & CD19 & 21 & $\begin{array}{l}\text { CRS/macrophage activation syndrome, endocarditis, } \\
\text { septic shock with liver failure, and extensive diffuse } \\
\text { large B cell lymphoma }\end{array}$ \\
\hline 2 & 48 & $\mathrm{~F}$ & ALL & $\mathrm{CD} 19$ & 3 & C. Difficile pseudonembranous colitis and CRS \\
\hline 3 & 55 & м & CLLSLL & CD19 & 90 & Aspergillus pneumonia \\
\hline 4 & 70 & м & DLBCL & CD19 & $\begin{array}{l}23 \text { (post-1. } \\
\text { infusion) } \\
9 \text { (post-2 } \\
\text { infusion) }\end{array}$ & $\begin{array}{l}\text { Renal failure secondary to extensive involvenent by } \\
\text { diffuse large B cell lymphoma. }\end{array}$ \\
\hline 5 & 62 & м & DLBCL & $\mathrm{CD} 19$ & $\begin{array}{c}477 \text { (post- }-1^{* 4} \\
\text { infusion) } \\
\begin{array}{c}436 \text { (post-2. } \\
\text { infusion) }\end{array}\end{array}$ & $\begin{array}{l}\text { Polymicrobial sepssts secondary to severe gratt versus. } \\
\text { host disease from allogeneic stem cell transplant for } \\
\text { traatment of refractory DLBCL }\end{array}$ \\
\hline 6 & 46 & $\mathrm{~F}$ & ALL & CD19 & 10 & Clostridium septicum bacteremia \\
\hline 7 & 60 & $\mathrm{~F}$ & MM & BCMA & $\begin{array}{c}470 \text { (post- } 1^{\star x} \\
\text { infusion) } \\
35 \text { (post-2 }-2^{\text {st }} \\
\text { infusion) }\end{array}$ & $\begin{array}{l}\text { Disseminated fungal infection and coasulase negative } \\
\text { staph bacteremia, secondary to pancylopenia and CRS }\end{array}$ \\
\hline 8 & 61 & $\mathrm{~F}$ & $\begin{array}{l}\text { Follicular } \\
\text { lymphoma }\end{array}$ & CD19 & 13 & Henorrthagic infarction of the brainstem. \\
\hline 9 & 67 & M & мM & $\mathrm{BCMA}$ & 198 & 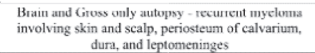 \\
\hline 10 & 62 & $\mathrm{~F}$ & CLL & CD19 & 4 & $\begin{array}{l}\text { Cardiac arrhythmia in the setting of mitral valve } \\
\text { annular talcinosis and cytokine release syndrome. }\end{array}$ \\
\hline 11 & 73 & м & $\begin{array}{c}\text { NHL- } \\
\text { BCLU } \\
\text { (Double } \\
\text { Hit) }\end{array}$ & CD19 & $\begin{array}{l}1439 \text { (post-1" } \\
\text { infusion) } \\
1390 \text { post } 2^{\text {at }} \\
\text { infusion }\end{array}$ & $\begin{array}{l}\text { Cardiac arrest frem stress cardiontyopathy duc to } \\
\text { scppis with nighth sided lung consolidations and } \\
\text { maxillary sinusitis }\end{array}$ \\
\hline 12 & 65 & м & DLBCL & CD19 & 47 & E. coli bacteremia, coagulopathy \\
\hline
\end{tabular}

timelines, microbiology data, cytokine levels, other pathology biopsies, and pertinent laboratory values. Histologic tissues were reviewed.

Results Twelve autopsies were performed since 2013. Patient characteristics and causes of death are summarized in table 1 . The most common cause of death was due to infectious causes $(n=6)$. Two patients (Patients 10 and 11) had cardiovascular related deaths. Six patients (Patients 1, 2, 6, 7, 10, 12) suffered from CRS in their post-infusion course, four of whom (Patients 1, 2, 7, 10) had CRS directly attributed as the cause of death. CRS was further complicated by immune effector cell-associated neurotoxicity syndrome (ICANS) in 5 patients (Patients 1, 5, 6, 7, and 12). CRS with ICANS was the second most common cause of death in patients treated with CAR T-cells. Three patients (Patients 1, 4, 9) had progression of disease that attributed to cause of death.

Conclusions CAR T-cell therapy is a highly effective treatment even for patients who have relapsed and/or refractory disease. Post-therapy complications range in severity and may be fatal in rare instances as in the patients summarized in this study. Infection, CRS with ICANS are the most common causes of death in our single institution study.

Ethics Approval The study was approved by Fred Hutchinson Cancer Research Center's Institutional Review Board, approval number 1837

Consent Written informed consent was obtained from the patient for publication of this abstract and any accompanying images. A copy of the written consent is available for review by the Editor of this journal.

http://dx.doi.org/10.1136/jitc-2020-SITC2020.0643

\section{OCULAR ADVERSE EVENTS ASSOCIATED WITH PROGRAMMED DEATH-1 AND PROGRAMMED DEATH LIGAND-1 IMMUNOTHERAPY}

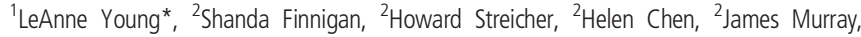
${ }^{1} \mathrm{H}$ Nida Sen, ${ }^{2}$ Elad Sharon. ${ }^{1}$ National Eye Institute, Cleveland, OH, USA; ${ }^{2}$ National Cancer Institute, Bethesda, MD, USA

Background The programmed death-1 (PD-1) and programmed death ligand-1 (PD-L1) inhibitors are increasingly studied and are known to have unique inflammatory side effects due to non-specific immune system activation. ${ }^{1}$ While rare, PD-1/PDL1 inhibitors can cause ocular toxicities, including inflammatory eye disease. $^{2}$ However, these ocular adverse events are less well-studied.

Methods This was a retrospective review of two adverse event (AE) monitoring databases maintained by the National Cancer Institute's Cancer Therapy Evaluation Program (CTEP), one of the largest public sponsors of clinical trials worldwide. One database (CTEP-AERS) is used for study sites to expeditiously report serious AEs for potential FDA review, while the other database (CDUS) is updated quarterly to reflect all the adverse events from the Phase 1 and Phase 2 trials in the CTEP network.

Results The two adverse event databases were queried for ocular adverse events up to May 19, 2020. A total of 331 adverse events from 259 patients were found. 73 patients (28\%) were exposed to nivolumab, 117 patients (45\%) were exposed to combination nivolumab and ipilimumab, 41 (16\%) were exposed to pembrolizumab, 26 (10\%) were exposed to atezolizumab, and $2(0.8 \%)$ were exposed to durvalumab. 59 adverse events from 47 patients were reported by the study 